\title{
PARA UM ESTUDO DO PROCESSO CRIADOR NA POESIA DE HERBERTO HELDER
}

João Décio

Herberto Helder (1) se constitui em figura de poeta que, gradativamente, vem firmando sua posição como um dos mais inquietantes e significativos da atual Literatura Portuguesa.

Autor de vários livros de poesia, como A Colher na Boca (19531960); Poemacto (1961), Lugar (1961-1962), A Máquina Lírica (1963), A Máquina de Emaranhar Paisagens, teve sua obra reunida em dois volumes: Poesia Toda I e II, em 1973. E autor ainda de dois poemas em prosa: Retrato em Movimento (1967) e Vocação Animal (1971), além de uma espécie de autobiografia, Apresentação do Rosto (1968), além dos contos Passos em Volta.

No presente estudo vamos tentar fixar alguns recursos de linguagem no seu discurso literário, para chegar à identificação de características do seu processo criador em poesia.

Antes, porém, de passarmos às considerações sobre o tópico que sscolhemos, queremos lembrar que até o momento a Herberto Helder foi dedicado um reduzido número de trabalhos, alguns versando sobre a obra poética, outros sobre suas narrativas curtas. Dentre os primeiros, António Ramos Rosa num capítulo do livro Poesia, Liberdade Livre ocupou-se do autor de Ofício Cantante; igualmente, Maria Lúcia Lepecki na revista Vozes, no 4 , publicou um artigo intitulado "Sobre a Poesia de Herberto Helder" Mais recentemente, Maria Lúcia dal Farra comentou extensivamente e em profundidade o poema "Para o leitor ler de/vagar" Nós, na revista Alfa no 17 iniciamos uma série de artigos intitulado "Introdução ao estudo da poesia de Herberto Helder" e que teve continuidade no no 20/21 da mesma revista. Madeira.

(1) - Herberto Helder nasceu a 23 de novembro de 1930, na ilha da 
Quanto ainda à poesia, Ruy Bello, num capítulo fundamental "Poesia e Arte Poética", (2) tenta ir a fundo na temática de Herberto Helder:

No que se refere aos contos, Massaud Moisés dedicou a eles um capítulo do seu livro $O$ Conto Português e nós, na revista Alfa no 16 publicamos uma resenha sobre Passes em Volta. Ao mesmo livro, Alexandre Pinheiro Torres dedicou breves páginas em Romance: Mundo en Equação. Carlos Felipe Moisés, num verbete em $A$ Literatura Portuguesa Moderna, organizado por Massaud Moisés, traçou um perfil do artista, no tocante à sua prosa e poesia .

Nesta oportunidade, pretendo estabelecer as características da linguagem da poesia de Herberto Helder que a fazem poética, auxiliando-nos vez ou outra dos conceitos de poesia que nos apresentam Carlos Bousoño (3), na linha da contemplação de um conhecimento e sua comunicação, na expressão metafórica do "eu", conforme Massaud Moisés (4), na fixação da eternidade no instante ou na palavra das origens, na acepção respectivamente de André Breton (5) e Octavio Paz (6) Outros conceitos como o de poesia como palavra original ou de Benedetto Croce, (7) como síntese de uma imagem e um sentimento que a anima poderão aqui ou ali nos interessar

$\mathrm{Na}$ esteira de Carlos Bousoño, Herberto Helder se revela primordialmente como um artista de conhecimento sensorial. Predominam nele os aspectos visuais e auditivos e que o encaminham para outros campos imagéticos, aliás, assinalados com justiça por Ruy Bello:

"Mas o próprio Herberto Helder sabe que a sua poesia é uma poesia escrita, uma poesia "para o leitor ler" Para a análise da origem desta sobrecarga que é a linguagem do nosso poeta, seria bom operarmos no estrado do "ponto de vista"

Herberto Helder é um poeta visual que, pelo exercício da imaginação, a breve trechos se torna visionário"

Os aspectos sensoriais, em especial, os visuais, pelo intenso cultivo dos pormenores associam a poesia de Herberto Helder à pintura de que resulta um irrecusável caráter plástico e ao mesmo tempo arquitetural:

(2) - In Na Senda da Poesia, pp. 237-258.

(3) - Teoria de la Expresión Poética

(4) - A Criação Literária.

(5) - Cong. Georges Mounin em La communication Poétique.

(6) - El Arco y La Lira.

(7) - La Poesia. 
"No sorriso louco das mães batem as leves gotas de chuva . Nas amadas caras loucas batem e batem os dedos amarelos das candeias. Que balouçam. Que são puras. Gotas e candeias puras. E as mães aproximam-se, soprando os dedos frios"

Aqui, igualmente à plasticidade visual associam-se realidades táteis a outras de caráter impressionista.

O impressionismo destas imagens acaba sendo uma das tônicas da póetica de Herberto Helder e configura uma dinâmica e uma agitação ao nível das imagens a confirmar uma linguagem de intensa mobilidade.

Se quisermos, contudo, caracterizar um aspecto permanente da expressão helderiana, temos de convir que se trata, primacialmente, de uma linguagem metafórica, naquilo que constitui a aproximação de duas realidades aparentemente distantes, mas que se associam por serem origem ou sede de coisas que apresentam afinidade. Aliás, é a crença na metáfora que leva Herberto Helder a processos de definição que aparecem invariavelmente em sua poesia:

"Eu procuro dizer como tudo é outra coisa"

No processo metafórico não é incomum vermos o poeta associar um dado sentimental com outro retirado da natureza (9), e que portanto, se resolve numa metáfora recorrente:

"e o coração é uma semente inventada"

A metáfora e a base metafórica é um dos fortes indícios da linguagem poética em Herberto Helder.

Mas há outro aspecto relevante que afirma a poesia e o poético nos poemas de Herberto Helder, configura exatamente pela tentativa de fixar e reter a eternidade no instante, em imagens que por vezes se sustentam num visionário sentido plástico:

"Aí eu poderia erguer-me na ponta dos pés e ficar para sempre, como uma chama que a noite viesse alimentar com sua própria matéria que se queima. Noite (10)

(8) - "Poesia e Arte Poética", in Na Senda da Poesia, p. 253 Poesia Toda I, p. 60 .

(9) - Em artigo anterior publicado sobre o assunto, lembrávamos o caráter elemental da poesia de Herbe:to Helder, constantemente recorrendo a aspectos da natureza: sol, lua, noite, dia, fruto, etc., etc.

(10) - Poesia Toda, I, pp.-152-153. 
ou em

$$
\begin{aligned}
& \text { "Porque vi crianças alojadas nos meus melhores instantes, e } \\
& \text { (11) }
\end{aligned}
$$

A fixação ou a retenção da eternidade no instante, idéia firmada por André Breton, como sendo exclusiva da poesia, remete naturalmente a outra tônica constante em Herberto Helder, que é a da realidade temporal, que o artista, não poucas vezes trabalha numa dimensão universalizante:

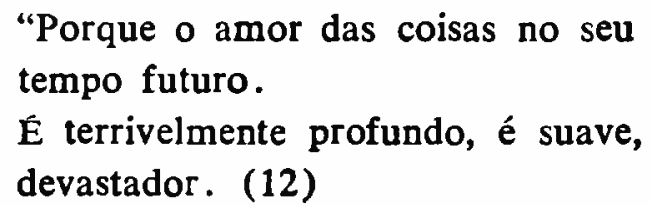

ou em

"Eudigo que ninguém se perdoa no tempo" (13)

Outro aspecto relevante na obra de Herberto Helder revela-se na preocupação com a construção do poema, com o rigor da expressão, na luta contra as palavras:

"Um poema cresce inseguramente

na confusão da carne."

Sobe ainda sem palavras, só ferocidade e gosto.

E o poema faz-se conta o tempo e a carne. (14)

Portanto, o poema se ergue poeticamente, ao nível do sangue, do suor e a sua realização semelha-se à relação erótica em ebulição.

Observa-se ademais, uma consciência constantemente voltada para a interrogação da palavra e das palavras, ao longo dos poemas de Herberto Helder, o que estabelece a presença irrecusável da metalinguagem na medida de uma expressão simbólica:

"A palavra esguia-se como um candelabro,

a voz ardia como um inesperado campo de giestas (15).

A linguagem poética também se realiza como liturgia da palavra, na busca de restaurar-lhe a presença, não raras vezes, por um processo anafórico e de intensificação:

(11) - Poesia Toda I, p. 189.

(12) - op. cit., p. 129.

(13) - op. cit., p. 128.

(14) - Poesia Toda - I, p. 38 e 39.

(15) - op. cit., p. 40 . 


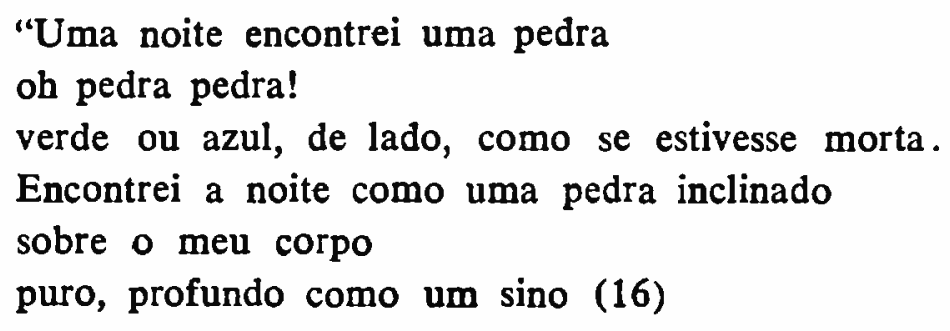

A demasiada preocupação com a palavra (e as palavras) e com o poema leva naturalmente a um processo artessanal, oficinal, ao nível do significante que, claro, terá efeito no significado. Pode ocorrer, nestes casos, uma animização das naturezas mortas:

"Havia rigor! Oh, exemplo extremo.

Havia uma essência de oficina.

Uma matéria sensacional no segredo das fruteiras, com suas maçãs centrípetas

e as uvas pendidas sobre a maturidade (17).

Observa-seaqui como em outras oportunidades, a linguagem poética socorrendo-se dos caracteres pictóricos, o que confirma a impressão que temos de uma poesia de indiscutível base plástica.

Mas, em inúmeros momentos, Herberto Helder extrapola a vivência particular deste ou daquele sentido, visual ou auditivo, para se concentrar numa totalização dos aspectos sensoriais que conduzem a um campo mais ou menos frequente em sua poesia que é o do erotismo. A presença da mulher, então, se faz soberana, vivida num plano sensorial associada à afetiva. Já podemos adiantar que é através dessas vias que o conhecimento se instala na poesia de Herberto Helder.

O aspecto conceptual, isto é, a presença das idéias se verifica em terceiro lugar, em, momentos que se acentua sua poesia como processo de definição.

Mas, tentando abrir brechas da linha do erotismo, convém lembrar inicialmente que Herberto Helder se aproveita de aspectos da natureza, para enfatizar o processo, na medida em que se confrontam, metafóricamente, as partes do corpo feminino com as flores:

"As mulheres têm uma assombrada roseira fria espalhada no ventre.

Uma quente roseira, às vezes, uma planta de treva.

((16) - op. cit., p. 152.

(17) - Poesia Toda - I, p. 129. 
As mulheres pensam como uma impensada roseira que pensa rosa.

Pensam de espinho para espinho, param de nó em nó.

As mulheres dão folhas, recebem um orvalho inocente (18).

ou

"Po:que as mulheres não pensam: abrem rosas tenebrosas, alagam a inteligência do poema .

São altas essas roseiras de mulheres inclinadas como sinos, como violinos, dentro do som (19).

Essa vivência da e em face das mulheres, em muitos momentos supera o enquadramento meramente erótico para atingir um processo de definição, reiterado várias vezes num dos poemas longos de Herberto Helder; "O Amor em Visita":

"Em cada mulher existe uma morte silenciosa (20)

ou e

"Começa o tempo onde a mulher começa, é sua carne que do minuto obscuro e morto se devolve à luz" (21).

A vivência da mulher, embora predomine na dimensão sensual e erótica, não se limita a isso, já que o amor ao nível do sentimento explode vigorosamente em muitos momentos do referido poema:

"Começa o tempo na insuportável ternura com que te adivinho, o tempo onde

a vária dor envolve o barro e a estreda, onde

o encanto liga a ave ao trevo (22).

A figura da mulher, seja vivida na dimensão sensual e erótica, seja no plano afetivo, percorre toda a melhor poesia de Herberto Hel-

(18) - Poesia Toda, p. I, p. 161.

(19) - Poesia Toda, p. I, p. 162.

(20) - Poesia Toda I, p. 29.

(21) - op. cit., p. 32 .

(22) - op. cit., p. 33. 
der, especialmente como definição e aceitação de que a grande experiência do homem advém daquela mesma vivência.

Mas, não só a mulher, como figura humana, surge como um dos temas caros ao autor de Lugar. Da mesma forma, a criança e por extensão, a infância aparece como tema relevante, não raro propulsor de momentos de universalização:

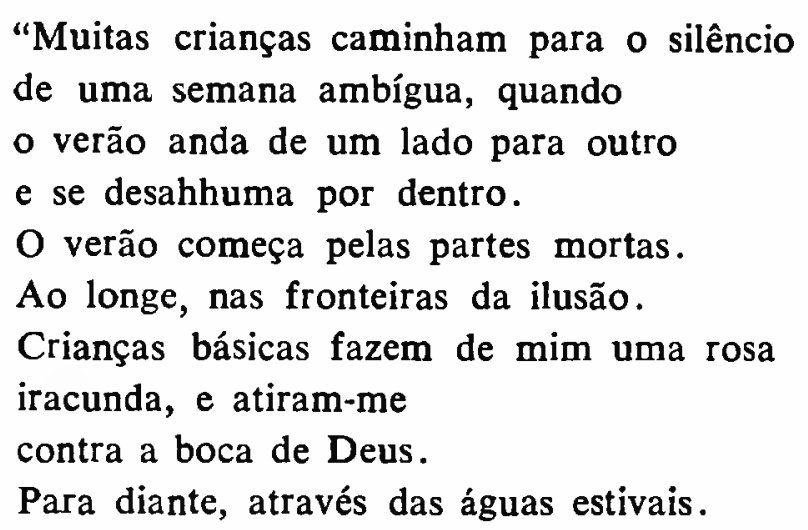

Finalmente, num plano amplo, a poesia de Herberto Helder se resolve em algumas tendências, dentre as quais se destacam o sensacionismo (plástico e dinâmico), o interseccionismo, de irrecusável influência pessoana, tudo se instalando num constante apelo ao onírico que o leva ao surrealismo.

Tal poesia se instala e centra-se no exato momento em que as sensações de toda natureza começam a substituir irresistivelmente o sen timento (embora este permaneça subjacente) e é neste sentido que ela se mostra extremamente atual.

Poeta riquíssimo já está a merecer trabalhos de fôlego que possam dar a dimensão ampla e total de sua cosmovisão e de seu processo criador Nós apontamos alguns breves aspectos para tentar iniciar um diálogo em torno de sua poesia.

Bibliografia

Poesia Toda - I e II, Lisboa, Plátano Editora, 1973.

Bibliografia:

Sobre o Autor:

BELlO, Ruy - Na Senda da Poesia, Braga, União Gáfica, 1969.

DÉCIO, João - "Instrodução ao Estudo da Poesia de Herberto Helder", Partes I e II, in Alfa n. ${ }^{\circ}$ 17, Marília, 1971. 
DECIO, João - "Introdução ao Estudo da Poesia de Herberto Helder", Partes III, in Alfa 20/21, Marília, 1975.

FARRA, Maria Lúcia Dal - "Para o leitor de /vagar Herberto Helder", in Revista Letras n. ${ }^{\circ}$ 24, Curitiba, 1975.

LEPECKY, Maria Lúcia - "Sobre a Poesia de Herberto Helder", in Vozes n. ${ }^{\circ}$, Rio de Janeiro, 1974.

MOISES, Calors Felipe - verbete sobre Herberto Helder, in A Literatura Portuguesa Moderna, Dir. de Massaud Moisés, São Paulo, Cultrix, 1974.

MOISÉS, Massaud - O Conto Português, São Paulo, Ed. Cultrix, 1975.

TORRES, Alexandre Pinheiro - Romance: Mundo em Equação, Lisboa, Portugália Editora, 1967.

Bibliografia geral:

BOUSOÑo, Carlos - Teoria de la Expresión Poética, Madrid, Edital Gredos, 1966.

CROCE, Benedetto - La Poesia, Bari, Gius. Laterza e Figli, 1946.

MOISÉS, Massaud $-R$ Criação Literária, São Paulo, Ed. Melhoramentos, 1967 